\title{
Power Stripping of Asbestos-Containing Insulation from Electrical Cable
}

\author{
Charles L. Blake' ${ }^{1}$ Giffe T. Johnson ${ }^{2}$, Raymond D. Harbison ${ }^{2}$ \\ ${ }^{1}$ Bureau Veritas, Kennesaw, GA, USA \\ ${ }^{2}$ Center for Environmental and Occupational Risk Analysis and Management, College of Public Health, \\ University of South Florida, Tampa, FL, USA \\ Email: gtjohnso@mail.usf.edu
}

How to cite this paper: Blake, C.L., Johnson, G.T. and Harbison, R.D. (2019) Power Stripping of Asbestos-Containing Insulation from Electrical Cable. Occupational Diseases and Environmental Medicine, 7, 65-74.

https://doi.org/10.4236/odem.2019.73006

Received: May 23, 2019

Accepted: August 2, 2019

Published: August 5, 2019

Copyright (c) 2019 by author(s) and Scientific Research Publishing Inc. This work is licensed under the Creative Commons Attribution International License (CC BY 4.0).

http://creativecommons.org/licenses/by/4.0/

\section{Open Access}

\begin{abstract}
Efforts to recycle copper from electrical conductors have led to the development of specialized machines, which automatically remove insulating covers from wires and cable products. In the past, certain wire and cable products were insulated using chrysotile asbestos. This research was undertaken to determine the asbestos fiber exposure risks associated with power stripping machinery to remove asbestos-containing insulation materials from electrical wire or cable. A Rigby Machinery, Inc., Model $4 \mathrm{H}$ electric powered wire/cable insulation stripping machine was acquired along with approximately $42 \mathrm{~m}$ of asbestos insulated cable. During two separate, but nearly identical, test sessions, a laborer used the wire stripper to remove the asbestos-containing insulation from the subject cable. This work took place within a closed metal building with a total interior volume of $2500 \mathrm{~m}^{3}$. Industrial hygiene personal and area air samples were collected for airborne fibers throughout all wire stripping periods. Collected air samples were analyzed using phase contract microscopy (PCM) and transmission microscopy (TEM). The results of analysis using PCM for personal samples $(\mathrm{n}=3)$ taken during periods of continuous cable stripping activity showed test period airborne fiber exposures ranging from 0.034 to 0.068 (mean $0.056 \mathrm{f} / \mathrm{cc}$ ). Follow-up analysis of these personal samples using TEM indicated asbestos adjusted PCM exposures ranging from 0.017 to 0.045 (mean $0.033 \mathrm{f} / \mathrm{cc}$ ). Area air samples taken at distances ranging from 2 to 9 meters from the wire stripper $(n=16)$ showed asbestos adjusted PCM concentrations ranging from less than 0.0001 to 0.041 $\mathrm{f} / \mathrm{cc}$ (mean $0.007 \mathrm{f} / \mathrm{cc}$ ). The process of power stripping asbestos-containing insulation from electrical wires and cables can cause exposure to airborne asbestos fibers. However, the levels of such exposure are not expected to exceed the current occupational exposure limits for asbestos of $0.1 \mathrm{f} / \mathrm{cc}$ as an $8-\mathrm{hr}$ TWA or $1.0 \mathrm{f} / \mathrm{cc}$ averaged over a 30 -minute exposure period.
\end{abstract}




\section{Keywords}

Asbestos, Exposure, Insulating Covers, Power Stripping, Electrical Wire, Chrysotile Asbestos, Asbestos Fibers, Asbestos-Related Disease, Asbestos-Containing Material

\section{Introduction}

Asbestos is a naturally occurring fibrous material that has long been mined and valued for its use in household, commercial, and industrial products due to its fire-retardant and insulating properties. During the mid to late 1970s, the demand for asbestos-containing materials (ACM) began to drop due to the increased scientific research that associated exposure to ACM to potential adverse health effects [1] and the subsequent regulatory requirements. Asbestos has been classified as a known human carcinogen and during residency in the lungs, a significant immunological response occurs that facilitates clearance [2] [3] that may also be the source of lung injury. The Occupational Safety and Health Administration (OSHA) has a Permissible Exposure Level (PEL) of $0.1 \mathrm{f} / \mathrm{cc}$ for asbestos. Several studies have shown that worker exposure to asbestos in occupations where routine exposure to ACM is expected (heavy construction equipment, automobile brakes, and plane parts) is consistent with the OSHA PEL [4] [5] [6] [7] [8]. Those findings are also consistent with the lack of epidemiological evidence for enhanced asbestos-related disease among motor vehicle mechanics and heavy equipment brake removal [9] [10].

To further document exposure assessments involving ACM in occupational settings, power stripping of asbestos-containing insulation from electrical cable is investigated. Operations that deal with large quantities of copper bearing electrical wires and cables may need the capability of extracting usable copper from waste conductors. Examples of such operations include; the manufacturers of wire and cable products, metal recyclers and public utility electric power transmission authorities. In most cases the value of copper must be weighted against the labor cost of extracting it from wire and cable products, which are often covered by electrical insulation.

Specialized machinery has been developed which can continuously cut through most insulation coverings and allow for relatively simple extraction of the copper conductors. Wire stripping machines vary in size from small, table-top models, to larger devices suitable for use in industrial settings. The Rigby Machinery, Inc. Model $4 \mathrm{H}$ used for this research is capable of continuously stripping the insulation from wires and cables varying in size from 3.0 to 25.4 mm diameter.

Prior to the mid 1980's, certain manufactures of wires and cables offered products which were insulated using chrysotile asbestos. The forms of this asbestos insulation varied according to wire designations and included; felted, 
braided and tape styles. Much of this asbestos insulation was saturated with proprietary, high melting temperature waxes, which rendered the otherwise hydrophilic chrysotile waterproof, and held even disaggregated asbestos fibers firmly in place.

Over the years since 1990, asbestos insulated wire and cable products have been the subject of industrial hygiene studies which sought to determine the possible levels of airborne fiber exposure associated with normal use of these products. Nearly all of these studies involved the cutting and stripping of asbestos insulation from wires or cables. Such cutting and stripping of insulation is typically done as part of the termination process, where conductor ends are exposed to allow connection at terminals. The results of nearly all such wire and cable studies involving asbestos insulation products, have consistently shown either no measurable airborne fiber exposure, or exposure at negligible levels. The only published study as of this date dealt with hacksaw cutting of armored Navy cable, and showed that during such cutting activities, “... airborne asbestos fibers of all sizes in air were not increased over detection limits." and further, that "The concentrations of airborne fibers greater than $5 \mu \mathrm{m}$ in length were not significantly different from the detection limits..." [11].

One of the available unpublished studies, included manual stripping of asbestos-containing wire insulation as part of a simulated copper recovery effort. However, prior to this study, no one has reported any measurements of possible airborne fiber exposure levels occasioned during use of a power stripper and asbestos insulated cable.

\section{Materials and Methods}

\subsection{The Wire Stripper}

The Rigby Model $4 \mathrm{H}$ wire stripper as used in this study, is an electric motor powered machine having four round cutting blades oriented in a circular array at $0^{\circ}, 90^{\circ}, 180^{\circ}$ and $270^{\circ}$. These blades engage the cable along its longitudinal axis making continuous cuts in the exterior insulation, while propelling the wires/cables through the machine. Available controls consist of; a cable size adjustment handle which brings the four blades inward or outward, cutter alignment screws which control the points of contact with the cable and electrical power switches which allow both forward and reverse cutter rotation. Cables with conductor sizes ranging from 20 gauge to 1 million circular mills can be accommodated by this machine, at throughputs up to approximately 3 $\mathrm{m} / \mathrm{sec}$.

Cable stripping using the Rigby $4 \mathrm{H}$, is accomplished by feeding the subject cable through the rear mounted guide opening and into the cutter array. Once energized, the Rigby $4 \mathrm{H}$ pulls the cable and cuts the insulation producing a multi stream output. After wires/cables have passed through the machine, the machine operator must then physically separate the copper conductors from the insulating materials, harvesting the copper and discarding the insulation. 


\subsection{Test Cable}

The Rigby $4 \mathrm{H}$ is designed to deal with a wide range of cable types and styles. For this testing, an asbestos insulated cable was utilized. The American Wire Gauge (AWG) designation of the test cable was 12 AWG 8 CDR BRD. This cable consisted of eight separate 12-gauge stranded copper conductors, each separately insulated with silicone rubber covered by individual, color coded, fibrous glass braids. The 8-conductor bundle was bound within a braided exterior insulation and had an overall exterior diameter of $18 \mathrm{~mm}$. Analysis of this exterior insulation using PLM indicated a $20 \%$ (by area) chrysotile asbestos content in conjunction with synthetic fibers and fibrous glass. A resinous binder was also present in the asbestos-containing insulation layer.

\subsection{Test Facility}

All testing was performed inside a metal building, which measured $18.5 \mathrm{~m}$ wide by $21.6 \mathrm{~m}$ deep with pitched roof $7 \mathrm{~m}$ high at center, sloping to $5.5 \mathrm{~m}$ high at the outside walls. Prior to testing, the building was thoroughly cleaned of visible dust and debris. The floor was prepared by first using a dry dust mop, followed by power washing using a floor cleaning machine, (Advance Machinery Co., Hydro Retriever model 260 BHD). After completion of pretest cleaning, the building was closed and air sampling was conducted to determine the background air quality. Throughout the period of each study, the test facility remained closed, and all heating, ventilating and air conditioning systems were shut down.

\subsection{Environmental Conditions}

On November 5, 2009, indoor temperature, relative humidity and carbon dioxide concentration measurements were made during testing using a TSI Incorporated Q-TrakTM IAQ monitor. For the January 29, 2010 session, indoor temperature and relative humidity measurements were made using a Kestral 3000 (Table 1). The Cartersville airport is equipped with a continuously broadcasting Automated Surface Observing System (ASOS) radio station, which was used to obtain data regarding ambient outdoor temperature, winds, barometric pressure and dew point. Outdoor ambient weather during the November 2009 testing included clear skies with light northerly winds and air temperatures ranging from $20^{\circ} \mathrm{C}$ to $21^{\circ} \mathrm{C}$. For the testing done during January 2010 , skies were overcast

Table 1. Environmental conditions.

\begin{tabular}{ccc}
\hline Test Date & Temperature $^{\bullet} \mathrm{C}$ & Relative Humidity \\
\hline November 5, 2009 Indoor & $29.4-30.8$ & $15.1-18$ \\
Outdoor Ambient & $16.6-18.8$ & $26.6-31.7$ \\
January 29, 2010 Indoor & $20-21$ & $26.6-30$ \\
Outdoor Ambient & $04-05$ & $85-90$ \\
\hline
\end{tabular}


with light winds out of the North North East and temperatures ranging from $4^{\circ} \mathrm{C}$ to $5^{\circ} \mathrm{C}$. Carbon dioxide measurements were made indoors only. Data ranged from 387 to $568, \times 452 \mathrm{ppm}$.

\subsection{Air Sampling and Analysis}

\subsubsection{Personal Samples}

Air sampling was conducted according to the NIOSH 7400/7402 sampling methodology, which incorporates use of $0.8 \mu \mathrm{m}$ pore size mixed cellulose ester membrane filters, housed inside $25 \mu \mathrm{m}$ diameter electrically conductive extended cowl cassettes [12] [13] [14]. For personal samples, Mine Safety Appliances; FloLiteTM battery operated, portable, air pumps were used, with airflow rates set in the 2 to 3 LPM range. Air sampling cassettes were placed within the laborer's breathing zone on his right shoulder. Personal air samples ran for the full period of each test which lasted 67 minutes during the first testing session and 28-minutes during the second. The laborer also wore additional, short-term personal samplers, which were placed on his right shoulder. These short-term air samplers were used for assessment of excursion limits and airborne fiber exposures.

\subsubsection{Area Air Samples}

For area air samples, Gast model (1531-1075-0288X), line operated, vacuum pumps drew air through cassette mounted $0.8 \mu \mathrm{m}$ pore sized membrane filters at flowrates nominally set in the 8 to 9 LPM range. The sample cassettes were suspended at breathing zone heights $(1.5 \mathrm{~m}$ above floor $)$ using metal stands. The open inlet ports of these cassettes were oriented in a downward facing attitude. Area air samples were located at two meters distance north, east, south and west from the stripping machine $(\mathrm{n}=4)$. Additional area air samples were located at the four compass points from the stripping machine $(n=4)$ at distances which ranged from 6 to 9 meters.

Air sampling flowrates were measured and recorded before commencement, and after completion of each testing session. These airflow measurements were performed using a primary standard, airflow calibrator, Bios International Model DC-1. Collected air samples and blanks were sealed and transported for analysis to Bureau Veritas North America, Inc's. American Industrial Hygiene Association (AIHA) and National Voluntary Laboratory Accreditation Program (NVLAP), accredited laboratory located in Kennesaw, Georgia.

To determine compliance with OSHA standards for asbestos, a phase contrast microscopy (PCM) analysis was performed, as specified in the NIOSH 7400 and OSHA ID-160 methods. Where questions exist regarding the composition of airborne fibers found using PCM, NIOSH 7402 analytical methodology is indicated. Those samples showing the presence of fibers (those longer than $5 \mu \mathrm{m}$ ) above the lower limit of detection, were submitted for further analysis using Transmission Electron Microscopy (TEM). This allowed the determination of asbestos vs. non-asbestos fiber ratios, which were then multiplied by the corres- 
ponding PCM derived analytical results, to yield the asbestos adjusted PCM airborne fiber concentrations. Airborne fiber exposure data derived using PCM analysis and qualified with TEM analysis focus on fibers longer than $5 \mu \mathrm{m}$ and wider than $0.25 \mu \mathrm{m}$, and are suitable for comparison against published health risk assessment databases.

\subsubsection{Background Air Samples}

Prior to each testing session, a set of five area air samples was collected from inside the closed testing facility. A second set of five concurrent area air samples was collected from outdoor ambient air. The outdoor samples were distributed upwind of the test building. These pretest samples were taken to determine the background airborne asbestos structure concentrations, if any, within the proposed test area. Similar air sampling was done following cleanup of the facility after completion of each testing session. Background and final clearance air sampling followed the US Environmental Protection Agency (EPA) Asbestos Hazard Emergency Response Act (AHERA) methodology, and collected samples were analyzed using TEM, according to AHERA rules. Airborne asbestos structure concentration data derived using AHERA methodology is suitable for use in determining the habitability of building space with regard to the presence of airborne asbestos.

\subsection{Work Procedures}

During each of two testing sessions, the laborer first distributed available electrical cable across the south side of the test area floor. He then cut 1.5 to $3 \mathrm{~m}$ long sections which he subsequently fed individually through the stripping machine. These cable sections were fed into the machine's inlet, then the stripped ends were manually pulled outwards from the machine's discharge side. Once clear of the machine, the stripping debris was piled on the floor until the laborer manually separated the internal conductors from the outer braided insulation. Prior to ending each test, the asbestos-containing insulation materials were placed into a metal trash container and sealed.

\section{Results and Discussion}

\subsection{Test Session 1}

The first of two cable stripping test sessions occurred on November 5, 2009 and lasted 67 minutes total duration. In all, approximately 30 meters of the 12 AWG 8CDR BRD cable was stripped of its outer braided insulation. The inner conductors were freed, however each retained its existing non-asbestos insulation, which consisted of silicone rubber covered by braided fibrous glass. No separate effort was made to remove these non-asbestos-containing insulation materials from the copper conductors.

When trying to feed cable through the stripping machine, the laborer experienced a stalling condition wherein the cable had to be manually pulled to sustain pass-through. When stalled, the cable and its insulation were subject to con- 
tinuous rubbing by the blades, such that at one time, during the first test session, what appeared to be smoke was observed rising from the cutting mechanism. Adjustment of cutting blade depth provided some correction of the stalling condition, however, the laborer had to manually pull all of the cable sections through the stripping machine.

In addition to cable stalling, the longitudinal cuts made in the braided exterior insulation were intermittent, thus not producing a complete separation of the insulation cover from the interior conductors. The laborer responded by manually separating the exterior, asbestos-containing braided insulation from the conductors. Because of the need for manual intervention in the cable stripping process, and the repeated contacts made by the laborer with the asbestos-containing insulation materials, the results of this testing are considered to represent a worst-case airborne fiber exposure situation.

Throughout this first testing period, personal air samples were collected, yielding one full-test period and two successive 30-minute samples. At any one time, the laborer was wearing two personal air samples. In addition, eight area air samples were collected from inside the test facility. These area samples ran roughly 14-minutes longer in duration than the personal samples, although, all full-term air samples included all of the wire stripping and associated debris sorting activities.

The results of analyzes for personal samples are summarized in Table 2.

For the 67-minute period, which included all stripping and sorting, a 0.068 $\mathrm{f} / \mathrm{ml}$ personal exposure concentration was indicated. The 30-minute duration air samples showed successive concentrations of 0.13 and $0.083 \mathrm{f} / \mathrm{ml}$. Further analysis of all samples using the TEM indicated the presence of non-asbestos fibers along with chrysotile such that after adjustment for asbestos content, a 0.045 $\mathrm{f} / \mathrm{ml}$ concentration resulted for the full test period, with 0.043 and $0.053 \mathrm{f} / \mathrm{ml}$ concentrations shown for the successive 30-minute segments.

Analysis of collected area air samples (see Table 3) showed the presence of both chrysotile and non-asbestos fibers. The average asbestos adjusted PCM airborne fiber concentration for samples taken at the $2 \mathrm{~m}$ distance was 0.017 $\mathrm{f} / \mathrm{ml}$. At the 6 to $9 \mathrm{~m}$ range, the average concentration dropped to $\leq 0.004 \mathrm{f} / \mathrm{ml}$.

Table 2. Personal airborne fiber test data.

\begin{tabular}{|c|c|c|c|c|c|c|c|c|}
\hline \multirow{2}{*}{ Test } & \multirow{2}{*}{ Procedure } & \multicolumn{2}{|c|}{ Sample Collection } & \multicolumn{2}{|c|}{ PCM Analysis } & \multirow{2}{*}{$\begin{array}{c}\text { TEM Analysis } \\
\text { Fiber Ratio }\end{array}$} & \multicolumn{2}{|c|}{ Asbestos Adjusted PCM } \\
\hline & & Time (min) & Volume (L) & $\emptyset^{\mathrm{a}}(\mathrm{f} / \mathrm{ml})$ & $\mathrm{TWA}^{\mathrm{b}}(\mathrm{f} / \mathrm{ml})$ & & $\varnothing(\mathrm{f} / \mathrm{ml})$ & TWA (f/ml) \\
\hline \multirow{3}{*}{1} & Power Strip 30M & 67 & 135.1 & 0.068 & 0.009 & 0.66 & 0.45 & 0.006 \\
\hline & of asbestos-containing & 30 & 60.5 & 0.13 & - & 0.33 & 0.43 & - \\
\hline & cable insulation & 30 & 60.5 & 0.083 & - & 0.64 & 0.53 & - \\
\hline \multirow{2}{*}{2} & $\begin{array}{l}\text { Power Strip } 12 \mathrm{M} \text { of } \\
\text { asbestos-containing }\end{array}$ & 28 & 77.6 & 0.034 & 0.002 & 0.50 & 0.017 & 0.001 \\
\hline & cable insulation & 27 & 80.2 & 0.066 & 0.004 & 0.57 & 0.038 & 0.002 \\
\hline
\end{tabular}

PCM and TEM analyses were completed according to the NIOSH Method 7400 and 7402, respectively. -, not applicable 30 minute excursion level. a Average airborne fiber concentration during sample duration; ${ }^{\mathrm{b}}$ TWA is 8 -hr TWA assuming no exposure other than during the sampling period. 
Table 3. Average airborne fiber concentrations test area.

\begin{tabular}{|c|c|c|c|c|}
\hline Test & Procedure & Location & $\begin{array}{l}\text { PCM } \\
(\mathrm{f} / \mathrm{ml})^{\mathrm{a}}\end{array}$ & $\begin{array}{c}\text { Asbestos } \\
\text { Adjusted } \\
\text { PCM }(\mathrm{f} / \mathrm{ml})^{\mathrm{a}}\end{array}$ \\
\hline \multirow{2}{*}{1} & Power Strip $30 \mathrm{M}$ & $\begin{array}{l}2 \mathrm{M} \text { distant from stripping } \\
\text { machine at compass points }\end{array}$ & 0.028 & 0.017 \\
\hline & cable insulation & $\begin{array}{c}6 \text { - } 9 \mathrm{M} \text { distance from stripping } \\
\text { machine at compass points }\end{array}$ & 0.015 & 0.004 \\
\hline \multirow{2}{*}{2} & Power Strip $12 \mathrm{M}$ of & $\begin{array}{l}2 \mathrm{M} \text { distant from stripping } \\
\text { machine at compass points }\end{array}$ & 0.017 & $\leq 0.004$ \\
\hline & cable insulation & $\begin{array}{c}6 \text { - } 9 \mathrm{M} \text { distance from stripping } \\
\text { machine at compass points }\end{array}$ & 0.013 & $\leq 0.004$ \\
\hline
\end{tabular}

Test Duration: Test $179-81 \mathrm{~min}$, Test $241-47 \mathrm{~min}$.

\subsection{Test Session 2}

The second of two testing sessions in this series took place on January 29, 2010 and lasted 47 minutes total duration, of which 28 -minutes involved actual wire stripping and associated debris sorting. During this session, the remaining $12+$ $\mathrm{m}$ of the 12 AWG 8CDR BRD cable was run through the wire stripper in $1.5 \mathrm{~m}$ sections. As with the earlier test session, no effort was made to remove the silicone rubber and fibrous glass insulation from the interior conductors once they had been released from the overall cable bundle.

Prior to conduct of this January 2010 test session, adjustments had been made to the wire stripper's cutter blade orientations. These adjustments were made in an effort to reduce or eliminate the cable stalling condition experienced during earlier testing. Ultimately cable thruput times were reduced, although the laborer still had to assist by manually pulling the cable through the machine.

Throughout the period of any wire stripping or debris handling, the laborer wore two personal air samplers. Analysis of these personal samples using PCM indicated exposures of 0.034 and $0.066 \mathrm{f} / \mathrm{ml}$ during the periods of wire stripping and debris handling. Follow-up analysis using TEM showed roughly $1 / 2$ of the collected fibers to be non-asbestos, resulting in asbestos adjusted PCM concentrations of 0.017 and $0.038 \mathrm{f} / \mathrm{ml}$.

Eight area air samples were taken with 4 at compass points 2 meters distant from the wire stripper, and the remaining 4 at 6 to 9 meters distance. At each range, 2 of the 4 area samples taken detected the presence of asbestos fibers. The average asbestos adjusted PCM concentrations at both ranges was $\leq 0.004$ $\mathrm{f} / \mathrm{ml}$.

\subsection{Discussion}

The results of this testing procedure show a potential for low level airborne chrysotile exposures associated with the use of power insulation stripping equipment on asbestos insulated wires and cables. Due to the difficulties experienced during these tests involving cable stalling, and the resultant need for 
manual intervention by the machine operator, these tests represent a worst-case exposure situation.

Prior to the conduct of formal testing, a variety of different cable types were run through the wire stripping machine. All but the 12 AWG 8CDR BRD used for testing had no asbestos content. It was observed that those cables having single stranded conductors passed through the stripping machine at rates equaling 1 to $3 \mathrm{~m} / \mathrm{s}$. Also the insulation coverings were continuously cut through to the conductors. When stripping insulation from such cables, the machine operator could remain at the input side, feeding cables segments into the cutter array. For cables on reels, the operator's role may be further reduced to simply manipulating the electrical controls.

Review of the personal air sampling data obtained during testing shows fairly consistent airborne fiber exposure data. For the initial testing, which continued over a 67 -minute time period, a $0.045 \mathrm{f} / \mathrm{ml}$ asbestos adjusted PCM concentration was indicated.

The 30-minute excursion level samples showed concentrations of $0.043 \mathrm{f} / \mathrm{ml}$ for the first 30 -minutes and $0.053 \mathrm{f} / \mathrm{ml}$ for the next. During the second testing session, actual wire stripping activities were completed within a 28 minute time period. Two personal samples taken concurrently showed asbestos adjusted PCM concentrations of 0.017 and $0.038 \mathrm{f} / \mathrm{ml}$. The somewhat lower personal exposures measured during the second testing session could have been caused by the reduced amount of wire stripping involved, or adjustments made to optimize the stripping machine.

\section{Conclusion}

The conditions observed in this investigation represented the worst-case scenario in a normal working environment with limited ventilation and frequent stalls in wire feeding that increased operator interaction with equipment. The investigation indicated that the process of power stripping asbestos-containing insulation from electrical wires and cables can cause exposure to airborne asbestos fibers. However, the levels of such exposure are not expected to exceed the current occupational exposure limits for asbestos of $0.1 \mathrm{f} / \mathrm{ml}$ as an 8 -hr TWA or $1.0 \mathrm{f} / \mathrm{ml}$ averaged over a 30-minute exposure period. This exposure analysis is consistent with a recent assessment of cancer risk among electricians that concluded exposure to chrysotile in electrical products is well below the OSHA permissible exposure limit and does not increase the risk of lung cancer and mesothelioma (7). In addition, this investigation demonstrates the importance of TEM adjustment of PCM findings to accurately characterize asbestos and non-asbestos form fibers in the work environment.

\section{Acknowledgements}

Conduct of both field tests funded by Anaconda. Development of original manuscript, no outside funding. Further work funded by the Center for Environmental and Occupational Risk Analysis and Management. 


\section{Conflicts of Interest}

$\mathrm{CB}$ has testified in matters involving asbestos-insulated wires and cables.

\section{References}

[1] Virta, R.L. (2006) Worldwide Asbestos Supply and Consumption Trends from 1900 through 2003. US Geological Survey Reston. https://doi.org/10.3133/cir1298

[2] Bernstein, D.M., et al. (2005) Comparison of Calidria Chrysotile Asbestos to Pure Tremolite: Final Results of the Inhalation Biopersistence and Histopathology Examination Following Short-Term Exposure. Inhalation Toxicology, 17, 427-449. https://doi.org/10.1080/08958370591002012

[3] Churg, A. (1994) Deposition and Clearance of Chrysotile Asbestos. Annals of Occupational Hygiene, 38, 424-425, 625-633.

[4] Blake, C.L., et al. (2006) Assessment of Airborne Asbestos Exposure during the Servicing and Handling of Automobile Asbestos-Containing Gaskets. Regulatory Toxicology and Pharmacology, 45, 214-222. https://doi.org/10.1016/j.yrtph.2006.04.007

[5] Blake, C.L., et al. (2009) Airborne Asbestos Exposure during Light Aircraft Brake Replacement. Regulatory Toxicology and Pharmacology, 54, 242-246. https://doi.org/10.1016/j.yrtph.2009.04.007

[6] Boelter, F.W., et al. (2007) Heavy Equipment Maintenance Exposure Assessment: Using a Time-Activity Model to Estimate Surrogate Values for Replacement of Missing Data. Journal of Occupational and Environmental Hygiene, 4, 525-537. https://doi.org/10.1080/15459620701411109

[7] Goodman, J.E., Peterson, M.K., Bailey, L.A., Kerper, L.E. and Dodge, D.G. (2014) Electricians' Chrysotile Asbestos Exposure from Electrical Products and Risks of Mesothelioma and Lung Cancer. Regulatory Toxicology and Pharmacology, 68, 8-15. https://doi.org/10.1016/j.yrtph.2013.10.008

[8] Pierce, J.S., et al. (2016) An Updated Evaluation of Reported No-Observed Effect Levels for Chrysotile Asbestos for Lung Cancer and Mesothelioma. Critical Reviews in Toxicology, 46, 561-586. https://doi.org/10.3109/10408444.2016.1150960

[9] Garabrant, D.H., et al. (2016) Mesothelioma among Motor Vehicle Mechanics: An Updated Review and Meta-Analysis. Annals of Occupational Hygiene, 60, 8-26. https://doi.org/10.1093/annhyg/mew038

[10] Madl, A.K., et al. (2009) Airborne Asbestos Concentrations Associated with Heavy Equipment Brake Removal. Annals of Occupational Hygiene, 53, 839-857.

[11] Millette, J. and Mount, M. (1999) Microscopical Studies of Asbestos Fiber Release during Cutting and Stripping of Wire Cables. Microscope, 47, 159-161.

[12] NIOSH 7400: Asbestos and Other Fibers by Phase Contrast Microscopy (PCM), Method 7400, NIOSH Manual of Analytical Methods, 4th Edition, US Department of HHS, NIOSH Publ. 94-113 (PCM).

[13] NIOSH 7402: Asbestos Fibers by Transmission Electron Microscopy (TEM), Method 7402, Issue 2, August 15, 1994, NIOSH Manual of Analytical Methods, 4th Edition.

[14] OSHA ID-160: OSHA Reference Method, June 17, 1986 (51FR 22612) and June 20, 1986 (29 CFR Parts 1910.1101 and 1926.110, Previously 1926.58). 